\title{
Medical assistance in dying: a structured postgraduate elective to build confidence in caring for patients
}

\author{
Joy Zhuo Ding, MD • Genevieve Casey, MD • Michael Kekewich, MA • \\ Lorne Wiesenfeld, MD • Viren N. Naik, MD, MEd, MBA
}

Received: 8 May 2019/Revised: 8 May 2019/Accepted: 10 May 2019/Published online: 31 May 2019

(C) Canadian Anesthesiologists' Society 2019

\section{To the Editor,}

Under Bill $\mathrm{C}-14,{ }^{1}$ healthcare professionals have been entrusted to legitimize, endorse, and implement medical assistance in dying (MAiD). To date, educational efforts have been focused on clinicians in practice to enhance awareness of this option for patients, and to establish best practices. While professional development activities continue, educational efforts should turn to developing curricula for clinicians in training, so they are better prepared to address MAiD requests or integrate care for these patients into their post-certification practice.

Despite faculty concerns regarding the ethics of and rights to refuse active participation in MAiD, the desire for learner experiences is undeniable. Falconer et al. surveyed 1,210 Canadian medical students and found that $71 \%$ were willing to provide MAiD. ${ }^{2}$ An anonymous survey of residents in the Queen's University Family Medicine

\section{J. Z. Ding, MD}

Division of Neurology, Department of Medicine, Faculty of

Medicine, University of Ottawa, Ottawa, ON, Canada

G. Casey, MD

Department of Medicine, Faculty of Medicine, University of Ottawa, Ottawa, ON, Canada

M. Kekewich, MA

Department of Clinical and Organizational Ethics, The Ottawa Hospital, Ottawa, ON, Canada

\section{Wiesenfeld, MD}

Department of Emergency Medicine, Faculty of Medicine, University of Ottawa, Ottawa, ON, Canada

V. N. Naik, MD, MEd, MBA ( $\varangle)$

Department of Anesthesiology and Pain Medicine, Faculty of Medicine, University of Ottawa, Ottawa, ON, Canada

e-mail: vnaik@royalcollege.ca program in 2016 found that formalized MAiD education is needed. ${ }^{3}$ Of the 62 residents who responded to that survey, only $11.3 \%$ felt competent discussing MAiD with their patients. Residents wished for more training in MAiD, including observing eligibility assessments (69\%) or provisions (37-55\%). Nevertheless, only $25.8 \%$ had any formal teaching related to MAiD.

Competencies for providing MAiD have been previously described. ${ }^{4}$ To our knowledge, a structured and formal approach to teaching these competencies during postgraduate education does not exist. Herein, we describe a four-week MAiD elective that we have developed that is available to trainees from any specialty to acquire the competencies required for MAiD assessment and provision.

Given the potential stress in the provision of this service, applications are accepted from senior trainees in the next to last or final year of their residency. Applications include a personal statement about the reasons for their interest in MAiD, the applicant's curriculum vitae, and an endorsement from their residency program director of good academic standing, maturity, and appropriateness of the elective to practice in the discipline.

Medical assistance in dying clinical experiences can vary and are unpredictable. Our program manages between 250 and 350 patient requests per annum. To ensure an appropriate experiential volume, the elective is available to only one trainee per block. The patient volume goals for optimal learning, as determined through faculty consensus, include ten assessments and three provisions. There is a graduated autonomy over the elective, starting with observation of assessments and provisions, but with rapid advancement to supervised independence. In addition to medical expertise competencies, communication and collaboration skills are obtained through interactions with 
patients, patients' families, and other health professionals on the MAiD team. Trainees are expected to complete the appropriate MAiD documentations, including mandatory provincial and federal reporting.

The elective has been designed to augment learning with patients through a formal curriculum. Knowledge and expertise are supplemented by discussing difficult case, and by reviewing critical incidents acquired over the experience of the service. Technical expertise in intravenous insertion is developed through experience in a high volume ( $>50$ patients) clinic, as necessary depending on experience in their base discipline. All trainees also complete a scholarly project related to MAiD during their elective.

An important concern is the potential psychologic burden in managing MAiD patients in a condensed elective block. As such, a key professional competency for development is resiliency. Residents are provided with the MAiD program ${ }^{5}$ and trainees have the opportunity to be debriefed by any faculty member throughout their elective. Additionally, residents have the choice to decline attendance at MAiD assessments or provisions at any time.

Thus far, six residents have completed our MAiD elective. A structured program evaluation is planned that will inform future iterations of the elective. We hope to provide an experience that will improve confidence in managing patients requesting MAiD and improve access to this option for patients in Canada.
Conflicts of interest None declared.

Editorial responsibility This submission was handled by Dr. Hilary P. Grocott, Editor-in-Chief, Canadian Journal of Anesthesia

Financial disclosures None.

\section{References}

1. Parliament of Canada. House of Commons. Bill C-14. Available from URL: https://www.parl.ca/DocumentViewer/en/42-1/bill/C14/royal-assent (accessed May 2019).

2. Falconer J, Couture F, Demir KK, Lang M, Shefman Z, Woo M. Perceptions and intentions toward medical assistance in dying among Canadian medical students. BMC Med Ethics 2019; 20: 22.

3. MacDonald S, LeBlanc S, Dalgarno $N$, et al. Exploring family medicine preceptor and resident perceptions of medical assistance in dying and desires for education. Can Fam Physician 2018; 64: e400-6.

4. Downar J, Green S, Radhakrishnan A, et al. An entrustable professional activity descriptor for medical aid in dying: a mixed-methods study. CMAJ 2018; 6: E657-63.

5. Ritchie K, Gérin-Lajoie C, Naik V. Medical assistance in dying. N Engl J Med 2017; 377: 896-7.

Publisher's Note Springer Nature remains neutral with regard to jurisdictional claims in published maps and institutional affiliations. 